\title{
Use of Smartphones by Art and Design Students for Accessing Library Services and Learning
}

Patrick Lo

Faculty of Library, Information \& Media Science, University of Tsukuba, Tsukuba, Japan

Allan Cho

Irving K. Barber Learning Centre, University of British Columbia, Vancouver, Canada

Man-Hon Leung, Dickson K.W. Chiu, Eddie H.T. Ko

Faculty of Education, University of Hong Kong, Hong Kong

Kevin K.W. Ho

School of Business and Public Administration, University of Guam, UOG Station, Mangilao, GU 96923

Corresponding author: Dickson K.W. Chiu

dicksonchiu@ieee.org

Acknowledgments:

This research is partially funded by the Faculty Research Fund, Faculty of Education, The University of Hong Kong 


\begin{abstract}
Purpose - This paper is to explore art and design students' use of smartphones for accessing library services and learning at the Hong Kong Design Institute (HKDI).

Design/methodology/approach - A questionnaire survey involving 51 HKDI students was conducted to examine the students' utilization of apps and the Internet on mobile devices to find information for the purpose of academic learning, social networking, and collaborative learning.

Findings - Survey results showed that while the HKDI students were all smartphone owners and active users of such mobile communication devices, only a minority of them "frequently" use these mobile devices for formal learning purposes. They demonstrated a keen preference to use search engines, social communications, and other diverse use of smartphones. Except for research and image/audio-visual needs, the rest of their needs and usage behaviour is similar to mainstream university students.

Practical implications - The results suggests opportunities for the libraries to develop services and facilities that could better fulfil students' information needs, and to improve the network coverage outside the library.

Originality/value - This is probably the first study of its kind to explore art and design students' use of smartphones for learning needs. In particular, the recent capability of smartphones and mobile Internet speed are comparable with desktops, it is vital to re-examine the much changed environment and user needs.
\end{abstract}




\section{Introduction}

Prior research in the adoption of e-learning systems (for example, Ho (2014)) has shown that the academic background of students would have an impact on their adoption behaviour. In this research, we would like to extend our investigation on the e-learning and online library usage behaviour of a specific group of students, i.e., students who are studying on the art and design areas. We perceive that they would have a different adoption and usage behaviour in e-learning and online library usage compared with students from other disciplines (Durling et al. 1996). In particular, as they are perusing in an academic discipline, which aims to develop their creativity through observations and inspiration seeking, they may have a very different needs of the services provided by the e-learning and online library systems. As a result, we would like to investigate into this group of students and discover their real need and requirement in E-learning and online library service.

\section{Aims of the Study}

This research attempts to explore how art and design students use smartphones for accessing library services and learning at a higher education institute specialized in delivering programmes in art and design. We hope our findings can help to improve the library services to this group of students. Not only has such information behaviour and practices amongst art and design students have been studied far less than students in many other academic disciplines, the particular use of contemporary mobile devices such as smartphones has to date been lacking. In particular, the recent capability of smart mobile devices and mobile Internet speed are comparable with desktops, it is vital to re-examine the much changed environment and user needs.

As such, our study examines a set of research questions that focus on exploring the information need of the art and design students as well as library usage on mobile platforms. We aim to understand whether and how the nature of art and design might influence the way they sought information via their smartphones for their artistic and creative endeavours. In other words, a better understanding amongst these group of art and design students can help those librarians working on 
an institution delivering programmes to develop more appropriate and better services, collections, facilities, m-library service instructions, planning, and so on.

\section{Research Questions}

To achieve the main aims of this study, we examine the students' utilization of apps and the Internet on mobile devices to find information for the purpose of academic learning, social networking, and collaborative learning at a higher institution specializing in delivering programmes in art and design. The research questions guiding this study are as follows:

RQ1. How do the art and design students use apps on mobile devices for collaborative learning purposes?

RQ2. How do the art and design students use apps on other mobile devices to find information for the purpose of academic learning?

RQ3. To what extent do the art and design students use the mobile devices for social networking purposes?

Through exploring these three RQs, we hope we can find out some insights in understanding the specific needs in the E-learning and online library services of art and design students.

\section{Literature Review}

The use of smartphones and mobile devices in academia has been well recorded (Krishnan, 2011; Paterson, et al., 2011; Aldrich, 2010) about millennial students as well-versed in this area of technology, and often change agents of post-secondary institutions catalysing IT adoption in teaching and learning. For example, Seeholzer and Salem (2010) learned in their study that students preferred using their mobile devices to interact with library resources and services, especially with research databases, library catalogue, and reference services and being contacted by the library using text messaging. Paterson and Low (2011) found in their study that the majority of students who plan to change their mobile handset would upgrade to a smartphones. Krishnan (2011) in particular 
articulates what remediation means for the academic library culture as a whole, observing the gradual shift from Web to mobile culture for the ING (information now generation).

A number of studies have emerged in the literature about how academic libraries have shifted their approaches to the technological fluidity of its student demographics. Lippincott (2008; 2010) has argued that academic libraries have the opportunity to extend new types of services to users of mobile devices and to develop, license, or otherwise make available scholarly contents configured for mobile devices. Recently, Bomhold (2015) has investigated the availability of discovery functions on mobile devices at academic research libraries and found that despite of some level of research functions available, there was a discrepancy between those that offered a full range of services and those that offered a minimal level.

In certain subject domains such as medicine, there has been particularly focused on the applications of smartphone use among students in medical programs. For example, Payne, Wharrad, and Watts (2012) found a high level of smartphone ownership and usage among medical students and junior doctors, with groups endorsing the development of more apps to support their education and clinical practice. The use of smartphones and mobile devices have continued to gain momentum in recent years, with both interns and practitioners integrating their use in the hospital and medical curriculum (Chatterley \& Chojecki, 2010; Franko \& Tirrell, 2012; Wallace et al., 2012).

Asia has particularly been early adopters of smartphones and mobile technologies and it is no surprise that many case studies in the early days of this emergent technology have been based from that region. Abdul Karim et al. (2006) explored the utilization of mobile phone services and perception of Malaysian university students on mobile phone uses in library and information services. The respondents' perceptions on the application of wireless hand services in the context of library and information services were found to be very positive. However, in a more recent study of mobile learning, university students from the Chinese University of Hong Kong, the City University of Hong Kong, the Nanyang Technological University and the University of Hong Kong (Ang et al., 
2012), most students in the study (93.8\% in total) possessed a mobile device and were adept at surfing the Web with their devices, but close to half of those were reluctant to use their mobile devices to access library services.

In taking a phenomenological approach, Chan et al. (2014) examined the reasons why students use mobile devices at the university. The findings indicated that students' smartphone use is subject to influences concerning the status of knowledge, from their peers, parents and the community at large, revealing smartphone adoption at a cultural rather than pedagogic level. Chun et al. (2012) also seemed to agree with the social use of mobile devices, revealing that smartphones are symbolic products that can signal affiliation and enhance the users' status in a group.

In summary, there has been little research on information-related behaviour of art and designs students. Even from the more studied academic libraries, there are also much discrepancy in service provision, diversified requirements among different users, and thus much room for improvement. Our earlier study on the Hong Kong Design Institute (HKDI) serves to inform and motivate the current mobile context of this study (Lo \& Chiu, 2015; Lo \& Chu, 2015). The students often require observation, note-taking, movement analysis, samples of materials, images, styles, patterns, textures, visual materials, etc., for inspiration and experimentation. Thus, in this study, we would further investigate into the e-learning and online library services of art and design students through recruiting students from the same institute. 


\section{Methodology}

\section{Research population and data collection}

To collect data for this research, we contacted the HKDI and obtained the permission to contact their students for data collection. The HKDI is a tertiary education institute managed by the Vocational Training Council (VTC) of Hong Kong, providing professional education in visual arts and design ranging from short certificate courses, higher diploma, to degree programs with subject specialisations including: digital animation, digital filmmaking, digital photography, interactive media, product design, and visual communication.

The Internet infrastructure of HKDI allows its students, as the same as the whole Hong Kong, to access to the global Web unrestricted, as opposed to limits on Web access in the mainland of the People's Republic of China, which blocks many social media and Websites due to political reasons. As of January 2015, the HKDI has about 7,000 students, and its library occupies a single floor of 2,800 square metres, with a collection of 80,000 items and 260 workstations well covered with wired and wireless network (Lo \& Chu, 2015). The library has put a lot of emphasis on e-services including OPAC, library information and booking, and e-databases. In particular, e-databases collecting image, clipart, and audio-visual materials are heavily used by students, as these are useful for art and design coursework.

All students enrolled at the HKDI were invited to take part in a survey to gather both quantitative and qualitative data. The survey questionnaires were delivered as printed copies at the HKDI Library in July 2014. The HKDI students entering the Library were asked to participate on a voluntary basis. As the study is focused on students only, the HKDI staff and other visitors were not invited to participate in this survey. The questionnaire asked specific questions such as the types of smartphones they owned, their subscriptions to Internet services, frequencies in using smartphones for learning, and social networking purposes. A total number of 51 respondents, 29 males and 22 females, completed the survey. 


\section{Data Analysis}

\section{Types of mobile devices used by students}

Findings of this study indicated that the student respondents surveyed were all smartphone owners, and also keen users of smartphone technologies. Out of all 51 students surveyed, only four (8\%) of them did not subscribe Internet services for their smartphones, and three of them indicated that they would use "free WiFi” for gaining access to the Internet. Meanwhile, out of the 48 respondents who agreed to provide us with information related to the models of smartphones that they are using, 33 (or 69\%) them were Android-based, and 15 (or 31\%) of them were operating on iOS (i.e., iPhone).

\section{General usage pattern of smartphone}

We noted that our subjects used their smartphone frequently. Based on a 5-point Likert Scale (5 = Very frequently; $1=$ Never) asking how often our subjects use their smartphone to access the Internet even when a PC is easily/readily available, we obtained an average value of 3.66. This indicated that our subjects often use their smartphone to access the Internet.

We only gather some information about the reasons for our subjects using their smartphones for accessing the Internet. The result is presented at Table 1. In brief, the major reasons for our subjects accessing the Internet with smartphone are mainly related to information search, such as they do not want to miss out information, and want to find quick answers and facts; as well as a replacement for computers. Also, some of them use it for passing away waiting time.

Table 1. Reasons for accessing the Internet with smartphones.

\begin{tabular}{lc}
\hline Reasons & Number (\%) \\
\hline Don't want to miss out on anything when on the go. & $36(70.6 \%)$ \\
Smartphone is good to pass away waiting time. & $33(64.7 \%)$ \\
Use smartphone when PC is not available. & $29(56.9 \%)$ \\
Use smartphone when I need quick facts/answers. & $29(56.9 \%)$ \\
Use smartphone when I am away from my computer. & $27(52.9 \%)$ \\
Want to use smartphone without being seen easily. & $8(15.4 \%)$ \\
Use smartphone because of lower costs than on other devices & $4(7.7 \%)$ \\
There is no other device with Internet access at home & $4(7.7 \%)$ \\
\hline
\end{tabular}


Concerning the general usage, we noted that most subjects would use their smartphones for daily communication with friends and family through email, SMS, as well as social media. They are also heavily relied on search engines (e.g., Google, Yahoo), as well as playing computer games. However, they were not eager to use the smartphone as a tool for reading. Plus, we observe that this group of subjects probably having risk averse personality as about half of them do not use their device for online banking, and one third of them never use the device for online shopping.

Table 2. Use of smartphones for everyday needs and other purposes $(\mathbf{N}=\mathbf{5 1})$

\begin{tabular}{lccccc}
\hline Purpose & Daily & Weekly & Monthly & < Once per Month & Never \\
\hline Communicating with friends and family & 46 & 2 & 1 & 1 & 1 \\
(Email, SMS, chat, etc.) & 42 & 7 & 2 & 0 & 0 \\
Activities with social media & 38 & 9 & 2 & 1 & 1 \\
Using search engines & 33 & 11 & 4 & 2 & 1 \\
Games, music, movies, TV series & 22 & 20 & 2 & 4 & 3 \\
Tools \& productivity software (calendar, & 21 & 13 & 10 & 4 & 3 \\
notes, to-do lists, etc.) & 18 & 19 & 7 & 5 & 2 \\
Hobbies, sports, fitness, travel & 15 & 16 & 7 & 9 & 4 \\
Accessing reference materials & 10 & 19 & 8 & 8 & 6 \\
(encyclopaedias, dictionaries, etc.) & 7 & 8 & 11 & 14 & 11 \\
Casual reading (non-academic) & 5 & 22 & 9 & 15 & 0 \\
Academic reading & 2 & 7 & 10 & 15 & 17 \\
Accessing libraries & 1 & 6 & 8 & 11 & 25 \\
Finding locations & & & & \\
Shopping & & & & & \\
Finance and banking & & & & & \\
\hline
\end{tabular}

\section{Use of smartphones for learning-related activities}

Concerning the use of smartphone for learning-related activities, we are in particular interested in how the students of art and design discipline are using the smartphone in learning and communication activities. Our results are summarized at Table 3.

First, we note that more than half of our subjects use their smartphones assessing reference materials and databases, as well as browsing website and social networking sites for learning purpose frequently (i.e., at least once per week). However, a bit to our surprise, they do not use their smartphones that often in reading journal articles, e-book, as well as searching library catalogue. We have further verified with our subjects and noted that the main reason for not assessing these 
functions using the smartphones mainly due to the design of the websites and applications, which make our subjects have difficulty in browsing the information concerned.

Second, we also note that more than half of our subjects are using the social networking sites and other apps of the phone in learning. In particular, they like to share their ideas and information by posting comments and uploading media files about their studies in the social networking sites, as well as using chatting and communication software to discuss their study issues with the classmates and instructors. These observations can be served as the evidence showing that our subjects are familiar with the use of technology in assisting their learning. The last but not least, we noted that our subjects are not that eager share information, except for sharing pictures on learning materials online.

Table 3. Using smartphones for learning purposes $(\mathbf{N}=\mathbf{5 1})$

\begin{tabular}{|c|c|c|c|c|c|}
\hline Purpose & Daily & Weekly & Monthly & $<$ Once per Month & Never \\
\hline \multicolumn{6}{|l|}{ General learning activities } \\
\hline $\begin{array}{l}\text { Accessing reference sources } \\
\text { (encyclopaedia, dictionary, etc.) }\end{array}$ & 23 & 16 & 4 & 6 & 2 \\
\hline Browsing on website for learning purpose & 21 & 14 & 7 & 4 & 5 \\
\hline $\begin{array}{l}\text { Browsing on social networking sites for } \\
\text { learning purpose }\end{array}$ & 18 & 12 & 12 & 4 & 5 \\
\hline Accessing and searching databases & 14 & 23 & 5 & 7 & 2 \\
\hline Viewing a video clip for learning purpose & 9 & 14 & 9 & 10 & 9 \\
\hline Browsing on learning resources sites & 8 & 15 & 15 & 8 & 5 \\
\hline Reading journal articles & 7 & 14 & 8 & 10 & 12 \\
\hline Searching with search engines & 6 & 11 & 11 & 12 & 11 \\
\hline $\begin{array}{l}\text { Listening to podcasts or other online audio } \\
\text { media for learning purpose }\end{array}$ & 4 & 12 & 7 & 9 & 19 \\
\hline Reading e-books & 3 & 15 & 8 & 13 & 12 \\
\hline Accessing and searching library catalogue & 3 & 10 & 10 & 15 & 13 \\
\hline \multicolumn{6}{|c|}{ Use of social networking sites and apps in learning } \\
\hline $\begin{array}{l}\text { Posting or commenting study related items } \\
\text { to social networking sites }\end{array}$ & 17 & 9 & 11 & 6 & 8 \\
\hline $\begin{array}{l}\text { Uploading photos or videos from your } \\
\text { smartphone to social networking sites for } \\
\text { learning purpose }\end{array}$ & 15 & 8 & 14 & 5 & 9 \\
\hline $\begin{array}{l}\text { Using email, SMS, MMS or chat apps for } \\
\text { study related issues with classmates or } \\
\text { instructors }\end{array}$ & 14 & 22 & 6 & 4 & 5 \\
\hline Transport files of retrieved resources & 13 & 16 & 9 & 9 & 4 \\
\hline $\begin{array}{l}\text { Discuss course materials, assignment, etc., } \\
\text { with classmates } \\
\text { Sharing of information for learning purpose }\end{array}$ & 12 & 20 & 15 & 2 & 2 \\
\hline
\end{tabular}




$\begin{array}{lccccc}\text { Planning or checking a personal schedule } & 12 & 10 & 6 & 10 & 18 \\ \text { Taking photos to record learning materials } & 11 & 18 & 5 & 6 & 11 \\ \text { Making notes with note-taking tools } & 6 & 18 & 12 & 4 & 11 \\ \text { Creating videos for study purposes } & 6 & 11 & 4 & 11 & 19 \\ \text { Creating documents } & 5 & 6 & 9 & 10 & 21 \\ \text { Recording sound file for creating } & 3 & 9 & 10 & 8 & 21 \\ \text { presentations } & 2 & 9 & 9 & 8 & 23 \\ \text { Recording a seminar or other presentation } & 2 & \end{array}$

\section{Barriers preventing students from engaging in online learning activities}

Table 4 presents our findings on barriers in general, which present our subjects engaging in online learning activities. In general, more than half of our subjects suggest that the loading speed for the learning materials is slow and there is a lack of WiFi and wireless service when needed. These two problems combined reflect that the Internet/mobile service providers of our subjects, as well as from the (learning) service provider. Apart from that, our subjects also suggest that there is a lack of specialized mobile apps for their learning service, as well as the reading content may be unable to present clearly in the smartphones are also problems. The last two problems are somehow issues, which the library concerned needs to address in the near future.

Table 4. Barriers preventing students from engaging in online learning activities $(\mathbf{N}=\mathbf{5 1})$

\begin{tabular}{lccccc}
\hline Barrier & $\begin{array}{c}\text { Main } \\
\text { barrier }\end{array}$ & $\begin{array}{c}\text { Medium } \\
\text { barrier }\end{array}$ & $\begin{array}{c}\text { Low } \\
\text { barrier }\end{array}$ & $\begin{array}{c}\text { No } \\
\text { impact }\end{array}$ & $\begin{array}{c}\text { Not } \\
\text { applicable }\end{array}$ \\
\hline Load speed is slow & 19 & 11 & 13 & 3 & 5 \\
No WiFi or wireless where needed & 18 & 13 & 11 & 4 & 5 \\
Lack of a specialized mobile apps & 13 & 9 & 16 & 6 & 7 \\
Difficulty reading content format & 9 & 20 & 12 & 6 & 4 \\
Difficulty with authentication & 9 & 11 & 17 & 11 & 3 \\
Webpage is not formatted for & 7 & 11 & 18 & 11 & 4 \\
smartphone & 6 & 5 & 20 & 14 & 6 \\
Screen size is too small & 5 & 10 & 18 & 14 & 4 \\
Text typing is difficult & & & &
\end{tabular}

To further investigate into the special need of art and design students, we further collected data to look into the mobile library services provided by the HKDI Library. Both the online library catalogue (OPAC) and the library account system have a mobile version that is optimized for mobile devices/smartphones. The HKDI Library also allows users to make reservations via its online 
booking system with their smartphones. Thus, we first investigate into whether our subjects are aware of these mobile apps, as well as their perceptions on them, which is summarized at Table 5.

There are several interesting observations. First, we noted that most subjects were not familiar with the online library services that were already available. Except for knowing how to check for the operating hours of library and the library map, which has about a quarter of subjects using it, only $15 \%$ or less of our subjects are using the other online library and resources. On the bright side, most of our subjects are having a positive attitude towards the online library services, as they are willing to use these services if they are available (and indeed, these services are available).

Table 5. Library services that students would like to use with smartphone. $(\mathbf{N}=\mathbf{5 1})$

\begin{tabular}{|c|c|c|c|c|c|}
\hline Library service & $\begin{array}{l}\text { Already } \\
\text { using }\end{array}$ & $\begin{array}{l}\text { Would definitely } \\
\text { use if available }\end{array}$ & $\begin{array}{l}\text { Would like to } \\
\text { use if available }\end{array}$ & $\begin{array}{c}\text { Not } \\
\text { interested }\end{array}$ & $\begin{array}{c}\text { Not } \\
\text { applicable }\end{array}$ \\
\hline $\begin{array}{l}\text { Check library hours, library } \\
\text { map }\end{array}$ & 14 & 5 & 19 & 10 & 3 \\
\hline $\begin{array}{l}\text { Access my library account, } \\
\text { renew \& request library } \\
\text { items }\end{array}$ & 8 & 12 & 16 & 10 & 5 \\
\hline Search library catalogue & 7 & 8 & 23 & 8 & 5 \\
\hline $\begin{array}{l}\text { Search \& access electronic } \\
\text { resources }\end{array}$ & 7 & 4 & 22 & 12 & 6 \\
\hline $\begin{array}{l}\text { Book a seat, a computer or a } \\
\text { study room }\end{array}$ & 5 & 13 & 17 & 10 & 6 \\
\hline $\begin{array}{l}\text { Provide comments \& } \\
\text { suggestions }\end{array}$ & 3 & 6 & 17 & 17 & 8 \\
\hline Contact librarian & 3 & 4 & 17 & 15 & 12 \\
\hline
\end{tabular}

To further investigate into how the Internet loading speed and the WiFi coverage issue affecting our subjects, we further look into the responses of our subjects with respect of the impact of Internet loading speed and WiFi coverage issue on the two major E-library services, i.e., accessing the reference sources and database. We only analyzed the data related to the subjects who claimed that they used the two services in a frequent basis (i.e., at least weekly) and considered the loading speed and WiFi coverage as barriers for using the two services concerned. Our data are presented at Table 6. 
Table 6. The impact of loading speed and WiFi coverage on major E-library services.

\begin{tabular}{lccc}
\hline Barrier / E-library service & Main barrier & Medium barrier & Low barrier \\
\hline Loading speed is slow & & & \\
Access reference source (daily/weekly) $(\mathrm{N}=34)$ & $13(38.2 \%)$ & $10(29.4 \%)$ & $11(32.4 \%)$ \\
Access database (daily/weekly) $(\mathrm{N}=34)$ & $15(44.1 \%)$ & $8(23.5 \%)$ & $11(32.4 \%)$ \\
WiFi coverage & & & \\
\hline Access reference source (daily/weekly) $(\mathrm{N}=30)$ & $12(40.0 \%)$ & $9(30.0 \%)$ & $9(30.0 \%)$ \\
Access database (daily/weekly) $(\mathrm{N}=33)$ & $15(45.5 \%)$ & $11(33.3 \%)$ & $7(21.2 \%)$ \\
\hline
\end{tabular}

As shown in Table 6, we noted that our subjects were of the view that both the slow loading speed and the poor WiFi connection are affecting the access of database more than the access of reference materials. This result may due to the reason that the file size of the archives in the database are usually larger than file size of the archives in the reference source and thus, the it has a more significant impact.

We also explored the perceived ease of use and perceived usefulness of three important mobile E-library services, i.e., mobile OPAC, remote access of electronic resources, mobile library account system. We developed three matrices to show the correlation between the ease of use and usefulness of these mobile systems are reported by our subjects, as shown in Tables 7 to 9 .

As shown in Table 7, a majority (41.2\%) of our subjects perceived that the OPAC is easy to use and useful, which is a very good sign. In other words, we can conclude that our subjects would have a high adoption of the OPAC system as predicted by the Technology Acceptance Model (Davis, 1989). However, we note that fewer subjects perceived that to gain remote access of electronic resources (31.4\%) and to access mobile library account (35.3\%) are easy to use and useful. Indeed, about a quarter of our subjects are of the view that these two systems are easy to use but not useful. In other words, the HKDI Library should consider to find methods to improve the design of these two systems with an aim to improve their usefulness, and try to find methods to change the negative perception of their users. 
Table 7. Usefulness and ease of use of mobile library catalogue (OPAC) $(\mathrm{N}=51)$.

\begin{tabular}{|c|c|c|c|}
\hline $\begin{array}{l}\text { Ease of Use/ } \\
\text { Usefulness }\end{array}$ & Easy to use & Difficult to use & Not Applicable \\
\hline Useful & $21(41.2 \%)$ & $2(3$ & $1(2.0 \%)$ \\
\hline Not useful & 10 (19.6\%) & 7 (13.7\%) & $\%)$ \\
\hline Not applicable & 0 & $1(2.0 \%)$ & $6(11.8 \%)$ \\
\hline
\end{tabular}

Table 8. Usefulness and ease of use of electronic resources via remote access $(\mathrm{N}=\mathbf{5 1})$.

\begin{tabular}{cccc}
\hline Ease of Use/ & Easy to use & Difficult to use Not Applicable \\
Usefulness & & $2(3.9 \%)$ & $1(2.0 \%)$ \\
\hline Useful & $16(31.4 \%)$ & $7(13.7 \%)$ & $5(9.8 \%)$ \\
Not useful & $13(25.5 \%)$ & 0 & $6(11.8 \%)$ \\
Not applicable & $1(2.0 \%)$ & 0 &
\end{tabular}

Table 9. Usefulness and ease of use of mobile library account system $(\mathrm{N}=\mathbf{5 1})$.

\begin{tabular}{cccc}
\hline $\begin{array}{l}\text { Ease of Use/ } \\
\text { Usefulness }\end{array}$ & Easy to use & Difficult to use Not Applicable \\
\hline Useful & $18(35.3 \%)$ & $2(3.9 \%)$ & $4(7.8 \%)$ \\
Not useful & $14(27.5 \%)$ & $5(9.8 \%)$ & $4(7.8 \%)$ \\
Not applicable & 0 & 0 & $4(7.8 \%)$ \\
\hline
\end{tabular}

\section{Discussion}

The survey results showed that our subjects from the HKDI were all smartphone owners, and were also active users. In particular, they frequently used smartphones for looking up quick facts for meeting their daily information needs, as well as to engage in other online recreational and social networking activities. On the other hand, despite respondents' smartphones were already equipped with a variety of devices, only a low proportion of them would "frequently" use these mobile devices for mobile learning purposes, such as engaging in reading e-books, viewing learning-related video clip and journal articles, etc.

\section{Mobile usage}

It should also be highlighted that regardless of daily-living needs or for meeting formal learning purposes, student respondents demonstrated a keen preference to use search engines (e.g., Google and Yahoo) for harvesting information from the Internet. Plus, the most popular application for communication was WhatsApp. YouTube was the most often-used online media platform for 
watching movies and listening to music. According to another survey carried out by Lo and Chu (2015) on information-seeking behaviour amongst the HKDI students, the Internet was found to be the most-chosen medium for finding inspiration amongst of the HKDI student respondents. In short, findings of the current study demonstrated that the Internet was of huge importance student population at HKDI, and are supportive to the results of the survey study by Lo and Chu (2015).

We also observed a relatively high number of student respondents indicated that they would use smartphones for communicating with other fellow students, perhaps for the needs of 'collaborative learning'. The tasks they performed include posting or commenting study related items to social networking sites, discussing course materials, assignment with classmate via social media applications, using email, SMS, MMS or chat apps for study-related issues. We attribute this phenomena is caused by the high percentage social networking tools usage of the HKDI students (Lo \& Chiu, 2015), despite the information-seeking activities of art and design students are generally perceived to be private endeavours.

\section{Adoption Obstacles}

However, we also discovered several factors, which acted as the barriers for our subjects to engage with the online library service. The first two were the slow loading speed and the limitation of Wifi or wireless connection. It is our understanding that these two problems were more likely caused by the cell phone service providers, which our subjects were depending on when they were off-campus. The popular e-database of image and audio-visual materials are also demanding ultra-high bandwidth and the students most probably use them for their design work on desktop or laptop computers, as observed earlier (Lo \& Chu, 2015). As the wired and wireless network coverage in the library is adequate, HKDI should investigate the Wifi coverage of the campus outside the library.

Further, it is argued because of such technical barriers, these subjects became less inclined to download and/or read lengthy articles with their smartphones. In addition, as explained by Dukic, 
Chiu and Lo (2015), smartphones are mostly used 'on-the-go', and such an environment is not suitable for academic learning. Another reason could be that the screen of a smartphone is small and is difficult to read (Dukic, Chiu \& Lo, 2015), and further in this case for the appreciation of artistic contents. This fact had been clarified with our subjects as they conjectured small keyboards and touchscreens was not a major barrier for them to engage in the service.

Concerning the online service that our subjects would like to use, we noted that quite a large number of our subjects expressed that they were not interested in providing comments and suggestions through the online system, or to use the online method to contact the librarian. This is probably because our subjects were associate degree students who just graduated from their high school, whom might not feel the need to engage in research consultations with the librarians for carrying out substantial academic research or discussions, such as requesting assistance from the librarians for finding scholarly journals. Therefore, they might not feel the need to use these types of online services.

Based on our observations, we noted that even though the HKDI Library has gone great lengths in making their digital resources and other services available online, students only expressed interests in a small number of mobile library services of administrative nature. In particular, they usually use the online system for looking up the library’s opening hours, performing self-renewals/requests via automated library account, and remotely booking of library facilities. As discovered in our survey, most students were not aware of the availability of such services. This is not an uncommon situation as Cassidy et al. (2014) had also noted a similar situation in their study. In other words, we would suggest the HKDI Library to put more efforts in promoting its services to its users. Probably, a well-designed publicity campaign should have been arranged at the beginning of every semester to make its users aware of the most updated information about the online library services provided by the HKDI Library.

\section{Comparison with other institutes}


Originally, it was assumed that the more studio-oriented, and less text-based curriculum at the HKDI might be the core reason behind students' infrequent use of their smartphones for using smartphones for formal learning purposes. However, when findings were compared against the results of another two cross-national comparative studies on $m$-learning amongst the library and information (LIS) students carried out by Ko et al. (2015) and Dukic et al. (2015), findings are surprisingly similar. In particular, learning activities involving communications and social media were so widely adopted amongst the student participants, as most of them are smartphone users and are ready for using their smartphones to engage with learning-related activities like discussing assignments, accessing resources and news from the course management and learning platform, checking course emails. This provides an important insight for the librarians: When we develop and revamp our online library service, we should take into account whether our service would be compatible in mobile devices. Plus, we should also make best use of the social media to push out information to our users.

According to Dukic et al. (2015), the frequencies of reading e-books and journals carried out by smartphones for academic purposes are much lower when compared with information-sharing activities for social networking purposes, for example, using smartphones for texting messages, exchanging personal photos, and so on. Generally speaking, there is not much difference found between the HKDI students and the LIS students from Hong Kong (at the University of Hong Kong) and Japan (at the University of Tsukuba) in terms of their using smartphones for everyday needs and learning purposes. Therefore, it is concluded that convenient access to information and satisfying instant information needs were found to be an important factor in the popularity of mobile technology amongst the student respondents.

\section{Conclusion}

Norris et al. (2011) predicted that mobile devices are becoming a widely-used learning device. Also, Dougherty (2010) predicted that mobile information patrons is increasing given the prevalence of 
wireless data communication technology. To further probe into the impact of mobile device in E-learning, this research is designed to fill a research gap on this topic about arts and design students (and somehow also on associate degree students) based on a quantitative survey analysis of students enrolled at the HKDI. The study examined the HKDI students' experiences in using or smartphones for study and learning purposes and their perception towards the usefulness and effectiveness of mobile phones for learning and other social communications in general. Their characteristics of m-learning usages amongst the HKDI students have also been highlighted. It is expected that results in this study could serve as a good reference for future researches.

Gaining an understanding of the current HKDI students’ mobile device usage is important for both the HKDI and its students, as it could provide an opportunity for the HKDI Library services provider to consider the implications of these findings, and use them to develop services and facilities that could better fulfil the students for their information needs. This study may also help the HKDI librarians to design more appropriate services in future, based on understanding the actual information needs and mobile device usage, or to assist them to recognize the range of m-library services available for meeting their learning and information needs. Findings of this study will provide some useful guidance for the second phase of our research, in which we intend to explore smartphone usage for learning more in-depth as well as looking at patterns amongst other academic institutes with also more geographical coverage.

Similar to other research, this research also has some limitations. First, the sample size was small as we have limited resources for data collection. The limitation of our resources also made us unable to make observation or detailed interviews. Therefore, the results would probably not to generalize and apply to the art and design student experiences across the same region. Plus, this study was limited to convenient sampling, which we invited students who visited the HKDI Library in person as our subjects. The last but not least, the closed-ended questionnaire design might have made the respondents to provide simplistic responses to complex issues. 
Our continuing research is to compare the mobile usage pattern of these students outside and inside the HKDI library in order suggest remedies to accessibility problems of library services encountered, in particular, Wifi coverage problems in the rest of the campus. On the other hand, we are planning to study the use of mobile apps in various real-life applications such as tourism (Chiu \& Leung, 2005), workforce management (Chiu, Cheung, \& Leung, 2005), and under emergency situations (Ng \& Chiu, 2006). 


\section{References}

Abdul Karim, N. S., Darus, S. H. and Hussin, R. (2006). "Mobile phone applications in academic library services: A students’ feedback survey”, Campus-Wide Information Systems, Vol. 23 No. 1, pp. 35-51.

Aharony, N. (2014). “Mobile libraries: Librarians’ and students’ perspectives”, College \& Research Libraries, Vol. 75 No. 2, pp. 202-217.

Ang, S., Chia, Y. B., Chan, I., Leung, K., Li, K. and Ku, K. M. (2012). “The survey on mobile library services in Hong Kong and Singapore academic libraries”, available at http://hub.hku.hk/handle/10722/152520 (accessed January 15, 2016).

Bomhold, C. (2015). "Research and discovery functions in mobile academic libraries: Are university libraries serving mobile researchers?”, Library Hi Tech, Vol. 33 No. 1, pp. 32-40.

Chatterley, T. and Chojecki, D. (2010). "Personal digital assistant usage among undergraduate medical students: Exploring trends, barriers, and the advent of smartphones”, Journal of the Medical Library Association, Vol. 98 No. 2, pp. 157-160.

Chiu, D.K.W., and Leung, H.F. (2005, August). Towards ubiquitous tourist service coordination and integration: a multi-agent and semantic web approach. In Proceedings of the 7th international conference on Electronic commerce (pp. 574-581). ACM.

Chiu, D.K.W., Cheung, S.C., and Leung, H.-F. (2005, January). A multi-agent infrastructure for mobile workforce management in a service oriented enterprise. In Proceedings of the 38th Annual Hawaii International Conference on System Sciences (pp. 85c-85c). IEEE.

Chun, H., Lee, H. and Kim, D. (2012). "The integrated model of smartphone adoption: Hedonic and utilitarian value perceptions of smartphones among Korean college students”, Cyberpsychology, Behavior, and Social Networking, Vol. 15 No. 9, pp. 473-479.

Cummings, J., Merrill, A. and Borrelli, S. (2010). "The use of handheld mobile devices: Their impact and implications for library services”, Library Hi Tech, Vol. 28 No. 1, pp. 22-40.

Dahlstrom, E., Dziuban, C. and Walker, J. (2013). "ECAR study of undergraduate students and information technology 2013”, Louisville, CO: EDUCAUSE Center for Analysis and Research.

Davis, F. D. (1989). "Perceived usefulness, perceived ease of use, and user acceptance of information technology”, MIS Quarterly, Vol. 13 No. 3, pp. 319-340.

Dresselhaus, A. and Shrode, F. (2012). "Mobile technologies \& academics: do students use mobile technologies in their academic lives and are librarians ready to meet this challenge?", Information Technology \& Libraries, Vol. 31 No. 2, 82-101.

Durling, D., Cross, N. and Johnson, J. (1996). "Personality and learning preferences of students in design and design-related disciplines”, IDATER 1996 Conference, Loughborough, UK: Loughborough University.

Farkas, M. (2010). “A library in your pocket”, American Libraries, Vol. 41 Nos. 6\&7, p. 38.

Franko, O. I. and Tirrell, T. F. (2012). “Smartphone app use among medical providers in ACGME training programs”, Journal of Medical Systems, Vol. 36 No. 5, pp. 3135-3139.

Ho, K. K. W. (2014). “The role of learners' academic background on e-learning: An empirical study on the use of discussion forum”, International Journal of Systems and Service-Oriented Engineering, Vol. 4 No. 4, pp. 51-64. 
Hong Kong Public Libraries (2014). "My Library - the official mobile app", available at http://www.hkpl.gov.hk/en/about-us/services/mobileapp.html (accessed January 15, 2016).

Keating, M. (2011). "Will they come? Get out the word about going mobile", The Reference Librarian, Vol. 52 No. 1, pp. 20-26.

Ko, E. H. T., Chiu, D. W. K., Lo, P., \& Ho, K. K. W. (2015). “Comparative study on m-learning usage among LIS students from Hong Kong, Japan and Taiwan”, The Journal of Academic Librarianship, Vol. 41 No. 5, pp. 567-577.

Krishnan, Y. (2011). “Libraries and the mobile revolution”, Computers in Libraries, Vol. 31 No. 3, pp. 6-11.

Lippincott, J. (2008). "Mobile technologies, mobile users: Implications for academic libraries", Association of Research Libraries: A Bimonthly Report, Vol. 261, pp. 1-4.

Lippincott, J. (2010). “Mobile reference: What are the questions?”, The Reference Librarian, Vol. 51 No. 1, pp. 1-11.

Lo, P. and Chiu, D.K.W. (2014). "Graffiti inside an art and design library? The Hong Kong Design Institute Library Experience”, Journal of East Asian Libraries, Vol. 2014 No. 159, pp. 40-48.

Lo, P. and Chu, W. (2015). "Information for inspiration: Understanding information-seeking behaviour and library usage of students at the Hong Kong Design Institute”, Australian Academic \& Research Libraries, Vol. 46 No. 2, pp. 101-120.

Ng, C. W., \& Chiu, D. K. W. (2006, January). e-Government integration with web services and alerts: a case study on an emergency route advisory system in Hong Kong. In Proceedings of the 39th Annual Hawaii International Conference on System Sciences, (Vol. 4, pp. 70b-70b). IEEE.

Payne, K. F. B., Wharrad, H. and Watts, K. (2012). "Smartphone and medical related App use among medical students and junior doctors in the United Kingdom (UK): A regional survey”, BMC Medical Informatics and Decision Making, Vol. 12 No. 1, p. 121.

Peter T. (2010). "Left to their own devices: The future of reference services on personal, portable information, communication, and entertainment devices”, The Reference Librarian, Vol. 52 Nos. 1-2, pp. 88-97.

Seeholzer, J. and Salem, J. (2011). "Library on the go: A focus group study of the mobile web and the academic library”, College \& Research Libraries, Vol. 72 No. 1, pp. 9-20.

Wilson, S. and McCarthy, G. (2010). “The mobile university: from the library to the campus", Reference Services Review, Vol. 38 No. 2, pp. 214-232.

Wallace, S., Clark, M. and White, J. (2012). “'It's on my iPhone': Attitudes to the use of mobile computing devices in medical education, a mixed-methods study”, BMJ Open, Vol. 2 No. 4, Article e001099. 